Provided for non-commercial research and education use. Not for reproduction, distribution or commercial use.

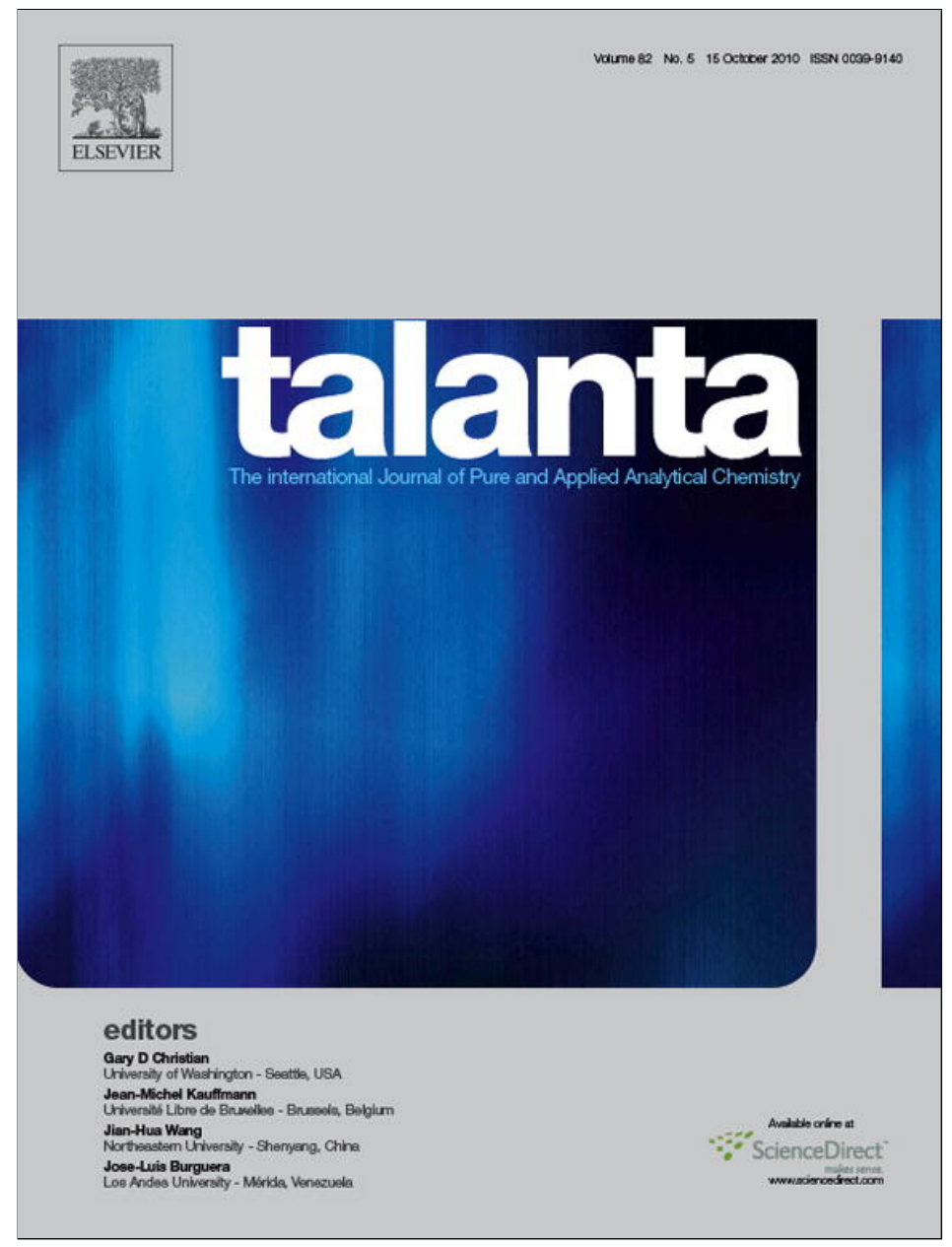

This article appeared in a journal published by Elsevier. The attached copy is furnished to the author for internal non-commercial research and education use, including for instruction at the authors institution and sharing with colleagues.

Other uses, including reproduction and distribution, or selling or licensing copies, or posting to personal, institutional or third party websites are prohibited.

In most cases authors are permitted to post their version of the article (e.g. in Word or Tex form) to their personal website or institutional repository. Authors requiring further information regarding Elsevier's archiving and manuscript policies are encouraged to visit:

http://www.elsevier.com/copyright 


\title{
Feasibility study on the use of near infrared spectroscopy to determine flavanols in grape seeds
}

\author{
Raúl Ferrer-Gallego, José Miguel Hernández-Hierro*, \\ Julián C. Rivas-Gonzalo, M. Teresa Escribano-Bailón \\ Grupo de Investigación en Polifenoles, Unidad de Nutrición y Bromatología, Facultad de Farmacia, \\ Universidad de Salamanca, Campus Miguel de Unamuno, E 37007 Salamanca, Spain
}

\section{A R T I C L E I N F O}

\section{Article history:}

Received 13 April 2010

Received in revised form 23 July 2010

Accepted 27 July 2010

Available online 3 August 2010

\section{Keywords: \\ Flavanols}

Grape seeds

Near infrared spectroscopy

Chemometrics

\begin{abstract}
A B S T R A C T
The potential of near infrared spectroscopy to determine the content of flavanols directly recording the infrared spectra of grape seeds has been evaluated. Moreover, the study shows the potential of this technique to obtain qualitative information related to the samples. In this case, the feasibility to discriminate between possible vineyards of origin has also been evaluated. Modified Partial Least Squares (MPLS) regression was used to develop the quantitative models in order to predict the content of flavanols. These models have been validated showing differences between $3.5 \%$ and $14.3 \%$ in the external validation. Moreover, Discriminant Partial Least Squares algorithm was used in the qualitative analysis to distinguish between two possible vineyards of origin and showed a high degree of accuracy. Prediction rates of samples correctly classified with a mean of $95 \%$ in internal validation and $97 \%$ in external validation were obtained. The procedure reported here seems to have an excellent potential for a fast and reasonably inexpensive analysis of these flavanols in grape seeds and could also be a tool to distinguish between possible vineyards of origin.
\end{abstract}

(C) 2010 Elsevier B.V. All rights reserved.

\section{Introduction}

Grape seeds represent only 0-6\% of berry weight, nevertheless they can provide a large source of phenolic compounds to red wines $[1,2]$. Phenolic composition in grape seeds depends on multiple factors such as variety, soil, viticulture practices, environmental conditions and degree of ripeness among others [3-5]. The presence and distribution of flavanols in grape seeds have been studied by several authors $[2,6-10]$ showing that monomers are usually the most abundant compounds. (+)-Catechin is often the most abundant individual flavanol in seeds, although (-)epicatechin is also well represented; however, some grape varieties display similar levels of both monomers or an even higher proportion of epicatechin. The oligomers of proanthocyanidins are mainly dimers and trimers in which the elemental units are essentially bound by type $\mathrm{C} 4 \rightarrow \mathrm{C} 8$ interflavan bonds. The dimer B2 and

Abbreviations: C, (+)-catechin; EC, (-)-epicatechin; B1, catechin- $(4 \beta \rightarrow 8)-$ catechin; B2, catechin- $(4 \beta \rightarrow 8)$-epicatechin; B3, catechin- $(4 \alpha \rightarrow 8)$-catechin; EEC, epicatechin- $(4 \beta \rightarrow 8)$-epicatechin- $(4 \beta \rightarrow 8)$-catechin; M, total monomers; $D$, total dimers; DG, total galloylated dimers; T, total trimers; TG, total galloylated trimers; TE, total tetramers; TT, total compounds; TTG, total galloylated compounds.

* Corresponding author. Tel.: +34 923294 537; fax: +34 923294515.

E-mail address: jmhhierro@usal.es (J.M. Hernández-Hierro). trimer EEC usually present the highest amounts in their respective oligomer groups. Another characteristic of the flavanol composition of grape seeds is the presence of derivatives esterified with gallic acid [8]. Levels of galloylated flavan-3-ols are noticeable in seeds although these compounds are usually in smaller amounts than the non-galloylated ones [9,11]. During maturation, changes in the flavanolic composition occur which affect the tannic intensity and astringency of seeds [12]. Monitoring these changes could be an important tool in deciding the optimal harvest time. This requires having rapid methods of analysis available with minimal or no sample preparation.

Near infrared spectroscopy (NIRS) provides fast, accurate, direct and non-destructive analysis. It allows qualitative and quantitative analysis to be performed in different matrices thereby reducing costs compared to wet chemical analysis and without generating waste. Therefore, this technique coupled with chemometric tools could provide an alternative method to undertake the analysis of proanthocyanidins in grape seeds.

The use of infrared spectroscopy has increased considerably in enological analysis. Among others, Fourier Transform Infrared Spectroscopy (FT-IR) has been used to identify varieties of Greek wines [13] and to determine phenolic compounds (pigmented polymers) [14], organic acids [15] and polysaccharides [16] in wine. Furthermore, this method has been used in order to determine the quality of grapes at harvest [17] and the mean degree of poly- 
merization in grape seed extracts [18]. Mid infrared spectroscopy has been applied to discriminate between organic or non-organic wines [19], to detect fermentation problems [20] and to verify the authenticity of some wines [21].

Near infrared spectroscopy (NIRS) has been used to classify grapes according to maturity, wines according to their geographic location [22-25] and to measure condensed tannins and dry matter in red grapes homogenates [26]. Moreover NIRS has been applied to determine mineral elements [27], reducing sugars [28], aromas [29] or phenolic compounds (malvidin-3-glucoside) in wine [30].

The aim of this work is to evaluate the potential of NIR technology to determine the main flavanols present in seeds. In addition to this, the distinction between two vineyards of origin was also evaluated. To our knowledge, this is the first time that NIRS has been used for these purposes using only intact grape seeds.

\section{Materials and methods}

\subsection{Samples}

Vitis vinifera L. cv. "Graciano" red grape samples were collected from two different vineyards located in La Rioja (Spain). P.O.D La Rioja is divided into regions according to their agro-climatic characteristics. Vineyard 1 is located in Logroño (Rioja Media) and vineyard 2 is located $40 \mathrm{~km}$ away, in Haro (Rioja Alta). The first region is under the influence of Mediterranean climate while Rioja Alta generally is cooler and is under the influence of Atlantic climate.

In order to have a wide range of flavanol concentrations, the samples were collected at different developmental stages from veraison (September) to over-ripeness (November) in two different vintages (2008 and 2009). In the case of 2008 vintage seven dates were taken into account for vineyard 1 and eight for vineyard 2 . For 2009 vintage the number of dates taken into account was six for vineyard 1 and seven for the vineyard 2 . Three groups of 150 berries per vineyard were collected at each date. A total of 84 samples were collected in this study corresponding to 39 samples from vineyard 1 and 45 samples from vineyard 2 . The berries were collected from both sides of vines located in different rows within the vineyard. Edge rows and the first two vines in a row were avoided. Berries were collected from the top, middle and bottom of the cluster and were immediately frozen and stored at $-20^{\circ} \mathrm{C}$ until analyses were performed. Grape seeds were separated manually from the integral grapes and the remaining pulp was removed with the aid of filter paper. Two aliquots were taken from each sample, one for the HPLC analysis and the other for the near infrared analysis.

\subsection{Chemical analysis}

Grape seeds separated manually were freeze-dried and ground to obtain a homogeneous powder for extraction. The grape seed powder was extracted with $75 \%$ methanol (Merck, LiChrosolv ${ }^{\circledR}$, Darmstadt, Germany) and the HPLC-DAD-MS analyses were carried out in accordance with Ferrer-Gallego et al. [12]. Quantification was performed by HPLC-DAD using calibration curves of (+)catechin, purchased from Sigma and of procyanidins obtained in our laboratory as described in González-Manzano et al. [31]. All analyses were performed in triplicate.

\subsection{Near infrared spectroscopy analysis}

The aliquot of intact grape seeds of each sample was used to carry out near infrared spectroscopy analysis. A Foss NIRSystem 5000 was used. Transport quartz cup capsules, known as rectangular cups with a window surface of $4.7 \mathrm{~cm} \times 5.7 \mathrm{~cm}$ and an

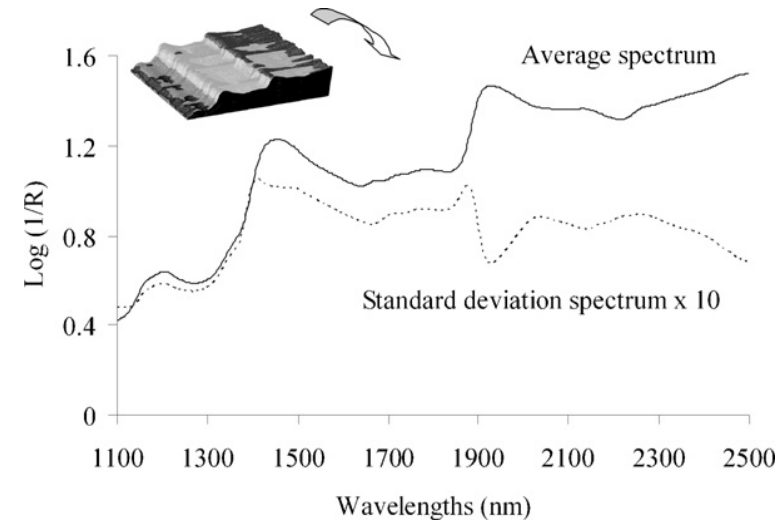

Fig. 1. Average and standard deviation (10 times amplified) spectrum of the whole group (84 samples) in the NIR zone between 1100 and $2498 \mathrm{~nm}$.

optical pathway of $1.7 \mathrm{~cm}$, were used in the $1 / 2$ full mode. Measurements were made between 1100 and $2498 \mathrm{~nm}$. The spectra were recorded at intervals of $2 \mathrm{~nm}, 32$ scans were performed for both reference and samples. To minimise the spectral sampling error, all the samples were analysed in triplicate and averaged to obtain each sample spectrum. The cup was washed with a mixture of methanol-distilled water (50:50), rinsed with distilled water and dried to avoid contamination among samples. A total of 84 spectra were recorded corresponding to the samples previously described. Fig. 1 shows the average and standard deviation (10 times amplified) spectrum of the whole group (84 samples) in the NIR zone between 1100 and $2498 \mathrm{~nm}$.

The software used was Win ISI ${ }^{\circledR}$ (v1.50) (Infrasoft International, LLC, Port. Matilda, PA, USA). This software allows not only the spectral acquisition but also the data treatment and the qualitative and quantitative models development. From the three samples of each date one (33\%) was allocated into the validation set and the other two (66\%) into the calibration set. The samples from each day were randomised allocated into calibration or validation set.

\subsection{Chemometric techniques}

A supervised pattern recognition technique, with a priori knowledge about the category membership of samples, was used in the qualitative analysis. Discriminant Partial Least Squares (DPLS) was used, which is a lineal, parametric, discriminant method and permits the modelling of classes. It has the advantage of being able to manage collinear variables, missing data and noisy variables and can deal with overlapped classes. The calibration was conducted by making a regression on the spectral information on all of group values, in this case defined as 1 or 2 . The regression method applied to this procedure is MPLS, which is a modification of a normal PLS $1[32,33]$.

Spectral pre-treatments are usually applied to NIR raw data, especially when these data are used to develop quantitative models. The effects of scattering were removed using Multiplicative Scatter Correction (MSC), Standard Normal Variate (SNV), Detrend $[34,35]$. Moreover, several mathematical treatments were tested in the development of the NIRS calibrations, a,b,c,d, where the first digit is the number of the derivative; the second is the gap over which the derivative is calculated; the third is the number of data points in a running average or smoothing, and the fourth is the second smoothing [36].

Prior to quantitative analysis an unsupervised pattern recognition technique, principal component analysis (PCA) was used in order to provide information about the latent structure of spectral data. This method provides not only information related to spectral outliers and distribution of samples in the created space, but is 
Table 1

Flavanol content in $\mathrm{mg} \mathrm{g}^{-1}$ of seed.

\begin{tabular}{lccrc}
\hline & Minimum & Maximum & Mean & SD \\
\hline C & 1.46 & 12.27 & 5.07 & 3.17 \\
EC & 2.27 & 18.92 & 7.06 & 4.78 \\
B1 & 0.64 & 1.30 & 0.84 & 0.15 \\
B2 & 1.13 & 2.49 & 2.01 & 0.30 \\
B3 & 0.50 & 1.27 & 0.79 & 0.18 \\
EEC & 0.98 & 2.26 & 1.49 & 0.36 \\
M & 4.03 & 31.20 & 12.12 & 7.86 \\
D & 4.12 & 5.30 & 4.76 & 0.31 \\
DG & 2.35 & 9.11 & 4.51 & 1.86 \\
T & 3.93 & 9.28 & 5.75 & 1.52 \\
TG & 1.68 & 5.37 & 2.94 & 0.85 \\
TE & 1.77 & 3.44 & 2.43 & 0.48 \\
TTG & 7.17 & 27.55 & 12.67 & 5.26 \\
TT & 25.46 & 74.33 & 39.77 & 13.14 \\
\hline
\end{tabular}

SD: standard deviation $(n=84)$.

also an important source of knowledge to create cross-validation groups used in the calibration process. Moreover, this is a useful tool to identify whether unknown samples do not belong to the spectral space created by the samples from which the equations were developed. In this case, the equations should not be used to make any prediction [36,37].

Calibrations were performed by modified partial least squares regression (MPLS), which is often more stable and accurate than the standard PLS algorithm. In MPLS, the NIR residuals at each wavelength, obtained after each factor has been calculated, are standardized (dividing by the standard deviations of the residuals at each wavelength) before calculating the next factor. When developing MPLS equations, cross-validation is recommended in order to select the optimal number of factors and to avoid overfitting [36]. For cross-validation, the calibration set is divided into several groups; each group is then validated using a calibration developed with the other samples. In this process other types of outliers are identified which present high residuals when they are predicted by the model. Finally, validation errors are combined into a standard error of cross-validation (SECV).

\section{Results and discussion}

\subsection{Chemical analysis}

Up to 36 flavanolic compounds were determined by HPLCDAD-MS. These compounds were organized in groups taking into account the existence of galloylation and the polymerization (monomers to tetramers). Moreover, major individual compounds were also considered. Table 1 only shows the range, mean value and
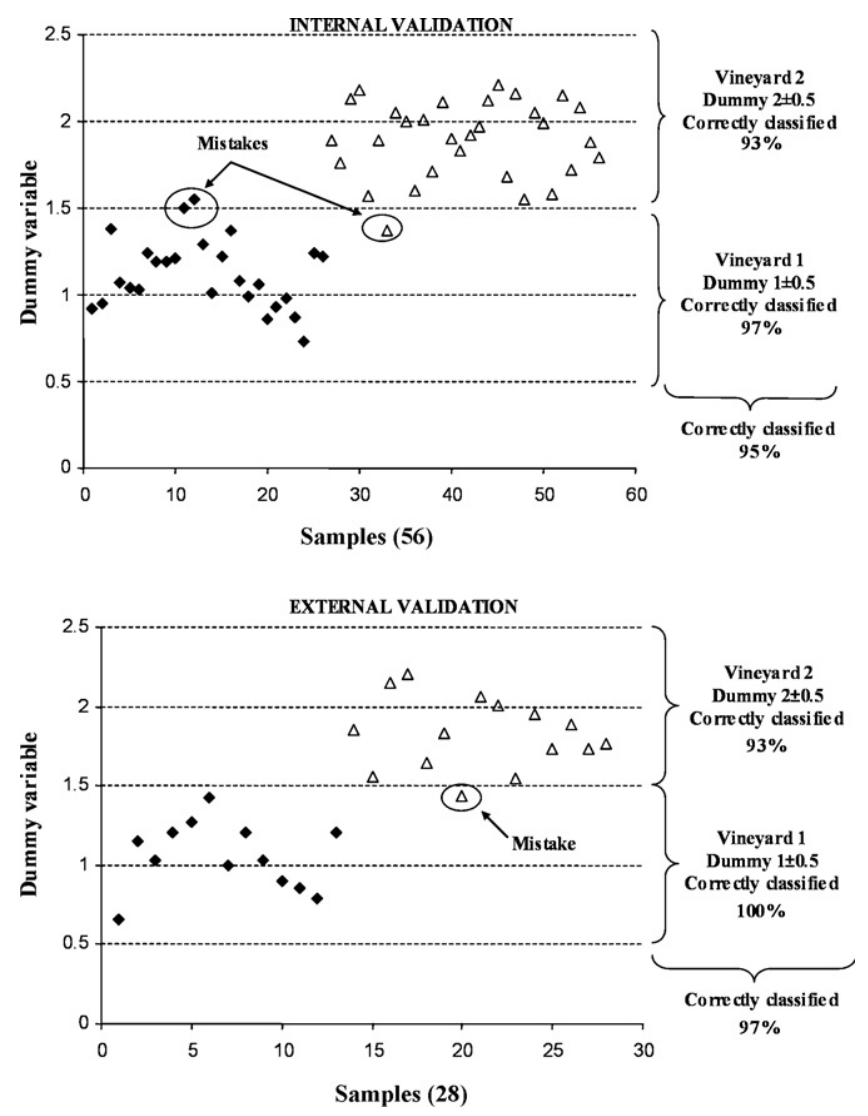

Fig. 2. Dummy variable plot of grape seed samples. Internal and external validation of the DPLS method.

standard deviation of the flavanol contents in the created groups and of the individual compounds that in the later development of NIR models achieved, suitable results.

\subsection{Near Infrared spectroscopy analysis and chemometric techniques}

\subsubsection{Qualitative analysis}

Modelling of the groups was carried out using the NIR raw spectral data and one dummy variable, whose values were 1 and 2 , thus the explicit algebraic models denominated DPLS were constructed. The model was developed using 11 PLS factors and presented an RSQ of 0.718 , SEC of 0.27 and SECV 0.33 . The spectral regions between $1100-1358$ and $1800-2100 \mathrm{~nm}$ showed important con-
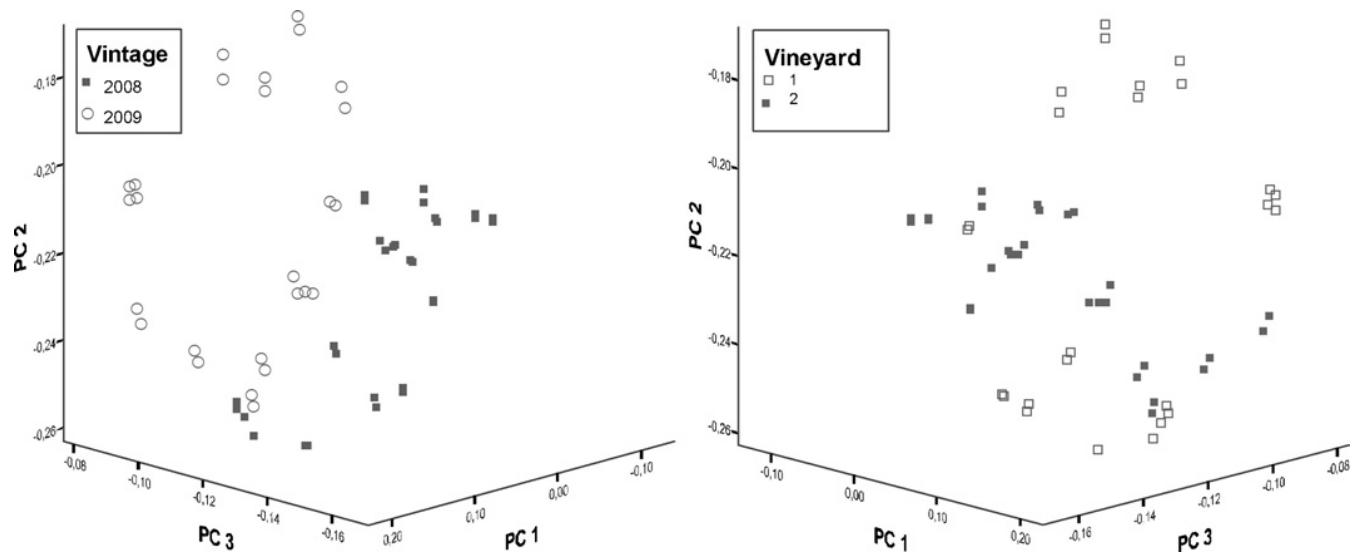

Fig. 3. Score plot of grape seed samples in the space defined by PC1 (87.6\%), PC2 (6.0\%) and PC3 (3.5\%). 
tributions to the model loadings and are mainly related to second overtones of $\mathrm{C}-\mathrm{H}$ and second overtones of the bonds present in the $\mathrm{COOH}$ groups, respectively [38,39]. The DPLS developed model predicted a dummy value for each sample and then the samples were allocated according to their predicted values \pm 0.5 in the corresponding vineyard with a dummy variable breakpoint of 1.5 . The predicted dummy variable plot for the qualitative model is shown in Fig. 2. Samples of vineyard 1 cluster around a dummy value of 1.0 , while those belonging to vineyard 2 around 2.0. Moreover, mistakes occurring in the internal and external validation were also indicated in this plot. These mistakes were samples incorrectly classified whose dummy values \pm 0.5 did not correspond to the correct one. A prediction rate of samples correctly classified was obtained (mean of $95 \%$ in internal validation and $97 \%$ in external validation). This demonstrates that NIR spectroscopy and discriminant DPLS analysis permit a clear differentiation between the two vineyards.

\subsubsection{Quantitative analysis}

As part of the quantitative analysis an SNV 2,4,4,1 spectral pre-treatment was applied to NIR raw data of samples from the calibration set and then principal component analysis was carried out. The spectral variability explained was $98.87 \%$ and 6 principal components were required. The Mahalanobis distance was calculated. This measure indicates how different the spectrum of the unknown sample is from the average spectrum in the calibration set. Samples with an $\mathrm{H}$-value (Mahalanobis distance) greater than 3 may be considered as not belonging to the population from which the equations were developed, for this reason 3 samples were removed. The risk of mistakes in the equations under practical conditions is very low or almost nil when using the standardized $H$-statistic during routine analysis of unknown samples. Samples with an $H$-value greater than 3 should not be used to make any prediction [36]. Fig. 3 shows the scores of the grape seeds in the space defined by the first, second and third principal components. This plot allows visualization of differences between the 2008 and 2009 vintages, whereas this is more difficult to observe in the case of the vineyard. Moreover, this plot shows that a noticeable spectral variability was taken into account to develop the NIRS models. Vineyards, ripeness and vintages were important sources of this variability.

Using the raw spectral data of the remaining samples (without $H$-outliers) and testing different spectral pre-treatments and allocating the corresponding HPLC-DAD quantitative flavanols' values to each sample, calibrations were performed by modified partial least squares regression (MPLS). In this method, the set of calibration samples is divided into a series of subsets in order to perform cross-validation to set the number of PLS factors and remove the chemical outliers. Using the $T \geq 2.5$ criterion, samples that present high residual value when they were predicted were eliminated from the set. The statistical parameters of the final calibration equations are shown in Table 2 where $N$ is the number of samples used to obtain the calibration equation after eliminating the samples for spectral ( $H$ criterion) or for chemical reasons ( $T$ criterion). The best of the different mathematical treatments, concentration range, and standard deviations are also shown. The spectral regions around $1150,1400,1650,1920$ and $2280 \mathrm{~nm}$ show important contributions to the models loadings. These could be related to first and second overtones of aromatic $\mathrm{CH}$ bonds (1650 and $1150 \mathrm{~nm}$ respectively), first and second overtones of $\mathrm{OH}$ alcohol functional group (2280 and $1400 \mathrm{~nm}$ respectively) and second overtone of $\mathrm{C}=\mathrm{O}$ bonds present in $\mathrm{COOH}$ carboxylic acids or COOR esters functional groups $(1920 \mathrm{~nm})$. These can be attributed to the chemical structure of the compounds analysed [38,39].

In order to evaluate NIR technology models an internal validation was carried out using samples that belonged to the calibration group after eliminating outliers. The prediction capacity of the model was assessed using the RPD (ratio performance deviation)

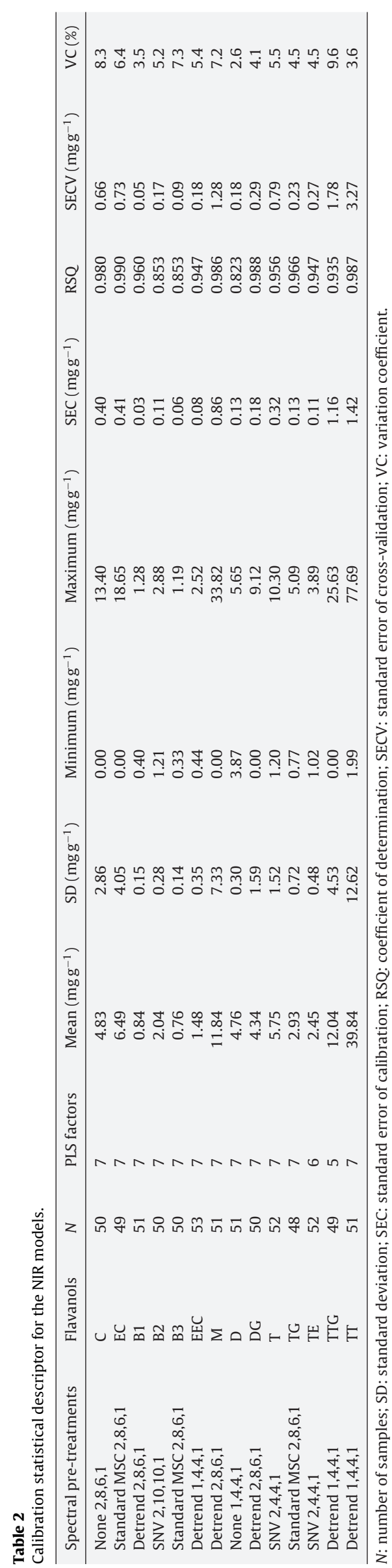


Table 3

Internal and external validations of quantitative NIR models.

\begin{tabular}{|c|c|c|c|c|c|c|c|}
\hline \multirow[t]{2}{*}{ Flavanols } & \multicolumn{4}{|c|}{ Internal validation } & \multicolumn{3}{|c|}{ External validation } \\
\hline & RPD & RSQ & $\operatorname{SEP}\left(\mathrm{mg} \mathrm{g}^{-1}\right)$ & $\operatorname{SEP}(C)\left(\mathrm{mg} \mathrm{g}^{-1}\right)$ & Difference (\%) & ANOVA ( $p$-value) & $\operatorname{SEP}\left(\mathrm{mg} \mathrm{g}^{-1}\right)$ \\
\hline C & 7.7 & 0.983 & 0.37 & 0.37 & 12.8 & 0.91 & 0.66 \\
\hline $\mathrm{EC}$ & 10.7 & 0.991 & 0.38 & 0.38 & 11.4 & 0.84 & 1.04 \\
\hline B1 & 5.4 & 0.966 & 0.03 & 0.03 & 4.8 & 0.92 & 0.06 \\
\hline B2 & 2.8 & 0.874 & 0.10 & 0.10 & 7.4 & 0.61 & 0.20 \\
\hline B3 & 2.8 & 0.874 & 0.05 & 0.05 & 8.3 & 0.48 & 0.12 \\
\hline EEC & 4.7 & 0.988 & 0.79 & 0.79 & 9.9 & 0.11 & 0.21 \\
\hline M & 9.3 & 0.954 & 0.07 & 0.08 & 12.6 & 0.95 & 1.37 \\
\hline $\mathrm{D}$ & 2.6 & 0.848 & 0.12 & 0.12 & 3.5 & 0.63 & 0.28 \\
\hline DG & 9.9 & 0.99 & 0.16 & 0.16 & 7.4 & 0.94 & 0.51 \\
\hline $\mathrm{T}$ & 5.2 & 0.962 & 0.29 & 0.29 & 10.6 & 0.21 & 0.82 \\
\hline TG & 6.0 & 0.971 & 0.12 & 0.12 & 11.2 & 0.87 & 0.51 \\
\hline $\mathrm{TE}$ & 4.7 & 0.953 & 0.10 & 0.10 & 10.2 & 0.88 & 0.37 \\
\hline TTG & 4.2 & 0.941 & 1.09 & 1.10 & 14.3 & 0.68 & 2.43 \\
\hline $\mathrm{TT}$ & 9.6 & 0.989 & 1.31 & 1.32 & 9.4 & 0.94 & 4.86 \\
\hline
\end{tabular}

RPD: ratio performance deviation; SEP: standard error of prediction; SEP (C): corrected standard error of prediction.

parameter, defined as the relationship between the standard deviation of the chemical method (SD ref) and that of prediction in the NIR model (SEP). The RPD value should ideally be greater than 2.5 . When this is the case it is assumed that the calibration model is adequate. All the models developed in this study present values higher than 2.5, therefore these models present an adequate prediction capacity [40]. Other descriptors of the internal validation are shown in Table 3.

We checked the robustness of the method by applying NIRS technology to 28 samples that did not belong to the calibration group. The calibration equations obtained during the work were applied and the predicted values were compared with the reference data. Table 3 also shows the results obtained in the external validation. The NIRS methodology and the reference data for flavanols were compared using one-way ANOVA (SPSS 13.0, Inc., Chicago, IL). All the $p$-values obtained were higher than 0.05 , thus there were no differences between the results obtained and it can be concluded that the method provides significantly equal values to those of the starting reference data. The differences between the HPLC reference method and the NIRS technique in the external validation were between $3.5 \%$ for D and $14.3 \%$ for TTG, the SEP values are also presented.

The biosyntesis of these compounds follow essentially the same course so inter-correlations among them could be expected [41]. The correlations evidenced among these compounds show that it is not possible to ascertain if the results of NIRS models for predicting the composition of these flavanols were due to their real absorbance or the correlation between them.

\section{Conclusions}

The results of this work show that the models developed using NIRS technology together with chemometric tools allow the content of flavanols to be determined in intact grape seeds throughout the maturation process and also specify the vineyard of origin. The procedure reported here seems to have an excellent potential for a fast and reasonably inexpensive analysis of these flavanols in grape seeds and to distinguish between possible vineyards of origin. Moreover, a comprehensive study should be made in order to evaluate factors, such as different production areas and grape varieties, in the development of these models.

\section{Acknowledgements}

Thanks are due to the Spanish MICINN (Project ref. AGL200805569-C02-01) and to Junta de Castilla y León (group GR133) for financial support. R. Ferrer-Gallego thanks the Spanish MICINN for the F.P.I. predoctoral scholarship. The authors also thank Bodegas RODA S.A. (Haro, La Rioja, Spain) for supplying the grape samples and Dr. I. González-Martín, who kindly allowed us to use the NIRS instrument. Thanks are also given to G. H. Jenkins for revision of the English version of the manuscript.

\section{References}

[1] B.S. Sun, T. Pinto, M.C. Leandro, J.M. Ricardo-Da-Silva, M.I. Spranger, Am. J. Enol. Viticult. 50 (1999) 179-184

[2] Y. Cadot, M.T. Minana-Castello, M. Chevalier, J. Agric. Food Chem. 54 (2006) 9206-9215.

[3] J.A. Kennedy, M.A. Matthews, A.L. Waterhouse, Phytochemistry 55 (2000) 77-85.

[4] V. Núñez, C. Gómez-Cordovés, B. Bartolomé, Y.-J. Hong, A.E. Mitchell, J. Sci. Food Agric. 86 (2006) 915-921.

[5] R. Rodríguez Montealegre, R. Romero Peces, J.L. Chacón Vozmediano, J. Martínez Gascueña, E. García Romero, J. Food Compos. Anal. 19 (2006) 687-693.

[6] A.G.H. Lea, P. Bridle, C.F. Timberlake, V.L. Singleton, Am. J. Enol. Viticult. 30 (1979) 289-300.

[7] M. Bourzeix, D. Weyland, N. Heredia, Bull. OIV 59 (1986) 1171-1254.

[8] J.M. Ricardo Da Silva, J. Rigaud, V. Cheynier, A. Cheminat, M. Moutounet, Phytochemistry 30 (1991) 1259-1264.

[9] C. Santos-Buelga, E.M. Francia-Aricha, M.T. Escribano-Bailón, Food Chem. 53 (1995) 197-201.

[10] A.M. Jordao, J.M. Ricardo Da Silva, O. Laureano, Am. J. Enol. Viticult. 52 (2001) 230-234.

[11] T. Escribano-Bailon, Y. Gutierrez-Fernandez, J.C. Rivas-Gonzalo, C. SantosBuelga, J. Agric. Food Chem. 40 (1992) 1794-1799.

[12] R. Ferrer-Gallego, M. García-Marino, J.M. Hernández-Hierro, J.C. Rivas-Gonzalo, M.T. Escribano-Bailón, Anal. Chim. Acta 660 (2010) 22-28.

[13] P.A. Tarantilis, V.E. Troianou, C.S. Pappas, Y.S. Kotseridis, M.G. Polissiou, Food Chem. 111 (2008) 192-196.

[14] J.S. Jensen, M. Egebo, A.S. Meyer, J. Agric. Food Chem. 56 (2008) 3493-3499.

[15] J.L. Moreira, L. Santos, Anal. Bioanal. Chem. 382 (2005) 421-425

[16] J.C. Boulet, P. Williams, T. Doco, Carbohydr. Polym. 69 (2007) 79-85.

[17] A. Versari, G.P. Parpinello, A.U. Mattioli, S. Galassi, Am.J. Enol. Viticult. 59(2008) 317-322.

[18] C.P. Passos, S.M. Cardoso, A.S. Barros, C.M. Silva, M.A. Coimbra, Anal. Chim. Acta 661 (2010) 143-149.

[19] D. Cozzolino, M. Holdstock, R.G. Dambergs, W.U. Cynkar, P.A. Smith, Food Chem. 116 (2009) 761-765

[20] A. Urtubia, J.R. Perez-Correa, F. Pizarro, E. Agosin, Food Control 19 (2008) 382-388.

[21] C.J. Bevin, R.G. Dambergs, A.J. Fergusson, D. Cozzolino, Anal. Chim. Acta 621 (2008) 19-23.

[22] J. Herrera, A. Guesalaga, E. Agosin, Meas. Sci. Technol. 14 (2003) 689-697.

[23] M. Le Moigne, C. Maury, D. Bertrand, F. Jourjon, Food. Qual. Prefer. 19 (2008) $220-231$.

[24] D. Cozzolino, H.E. Smyth, M. Gishen, J. Agric. Food Chem. 51 (2003) 7703-7708.

[25] L. Liu, D. Cozzolino, W.U. Cynkar, M. Gishen, C.B. Colby, J. Agric. Food Chem. 54 (2006) 6754-6759.

[26] D. Cozzolino, W.U. Cynkar, R.G. Dambergs, M.D. Mercurio, P.A. Smith, J. Agric Food Chem. 56 (2008) 7631-7636.

[27] D. Cozzolino, M.J. Kwiatkowski, R.G. Dambergs, W.U. Cynkar, L.J. Janik, G Skouroumounis, M. Gishen, Talanta 74 (2008) 711-716.

[28] J. Fernandez-Novales, M.I. Lopez, M.T. Sanchez, J. Morales, V. GonzalezCaballero, Food Res. Int. 42 (2009) 285-291. 
[29] H.E. Smyth, D. Cozzolino, W.U. Cynkar, R.G. Dambergs, M. Sefton, M. Gishen, Anal. Bioanal. Chem. 390 (2008) 1911-1916.

[30] D. Cozzolino, M.J. Kwiatkowski, M. Parker, W.U. Cynkar, R.G. Dambergs, M. Gishen, M.J. Herderich, Anal. Chim. Acta 513 (2004) 73-80.

[31] S. Gonzalez-Manzano, C. Santos-Buelga, J.J. Perez-Alonso, J.C. Rivas-Gonzalo, M.T. Escribano-Bailon, J. Agric. Food Chem. 54 (2006) 4326-4332.

[32] S. Lars, W. Svante, J. Chemometr. 1 (1987) 185-196.

[33] D.L. Massart, B.G. Vandeginste, L.M. Buydens, P.J. Lewi, J. Smeyers-Verbeke, S.D. Jong, Handbook of Chemometrics and Qualimetrics, Elsevier Science Inc., 1998.

[34] P. Geladi, D. MacDougall, H. Martens, Appl. Spectrosc. 39 (1985) 491500.

[35] M.S. Dhanoa, S.J. Lister, R.J. Barnes, Appl. Spectrosc. 49 (1995) 765-772.
[36] J.S. Shenk, M.O. Westerhaus, Routine Operation, Calibration, Development and Network System Management Manual, NIRSystems, Silver Spring, MD, USA, 1995.

[37] R.G. Brereton, Chemometrics: Data Analysis for the Laboratory and Chemical Plant, J. Wiley, Chichester, West Sussex, England, 2003.

[38] B.G. Osborne, T. Fearn, P.T. Hindle, Practical NIR Spectroscopy with Applications in Food and Beverage Analysis, Longman Scientific \& Technical/Wiley, Harlow, Essex, England/New York, 1993.

[39] H.W. Siesler, Y. Ozaky, S. Kawata, H.M. Heise, Near Infrared Spectroscopy: Principles, Instruments, Applications, Wiley-VCH, Weinheim, Germany, 2002.

[40] P.C. Williams, D.C. Sobering, J. Near Infrared Spectrosc. 1 (1993) 25-32.

[41] J.B. Harborne, The Flavonoids: Advances in Research Since 1986, Chapman \& Hall, London, England, 1994. 